\title{
Properties of Pain Assessment Tools for Use in People Living With Stroke: Systematic Review
}

\author{
Sophie Amelia Edwards ${ }^{1}$, Antreas loannou ${ }^{2}$, Gail Carin-Levy ${ }^{3}$, Eileen Cowey ${ }^{4}$, \\ Marian Brady ${ }^{5}$, Sarah Morton ${ }^{6}$, Tonje A. Sande ${ }^{7}$, Gillian Mead ${ }^{6}$ and Terence J. Quinn ${ }^{1 *}$ \\ ${ }^{1}$ Institute of Cardiovascular and Medical Sciences, University of Glasgow, Glasgow, United Kingdom, ${ }^{2}$ Internal Medicine \\ Department, Nicosia General Hospital, Strovolos, Cyprus, ${ }^{3}$ School of Health Sciences, Queen Margaret University, \\ Edinburgh, United Kingdom, ${ }^{4}$ School of Medicine, University of Glasgow, Glasgow, United Kingdom, ${ }^{5}$ NMAHP Research \\ Unit, Glasgow Caledonian University, Glasgow, United Kingdom, ${ }^{6}$ Centre for Clinical Brain Sciences, University of Edinburgh, \\ Edinburgh, United Kingdom, ${ }^{7}$ Centre for Medical Informatics, Usher Institute, University of Edinburgh, Edinburgh, \\ United Kingdom
}

OPEN ACCESS

Edited by:

Valerie Moyra Pomeroy, University of East Anglia, United Kingdom

Reviewed by: Jelle Demeestere, University Hospitals Leuven, Belgium Anna Danielsson, University of Gothenburg, Sweden

*Correspondence: Terence J. Quinn terry.quinn@glasgow.ac.uk

Specialty section: This article was submitted to

Stroke,

a section of the journal

Frontiers in Neurology

Received: 01 April 2020

Accepted: 25 June 2020

Published: 11 August 2020

Citation:

Edwards SA, loannou A, Carin-Levy G, Cowey E, Brady M, Morton S, Sande TA, Mead G and Quinn TJ (2020) Properties of Pain Assessment Tools for Use in People Living With Stroke: Systematic Review. Front. Neurol. 11:792. doi: 10.3389/fneur.2020.00792
Background: Pain is a common problem after stroke and is associated with poor outcomes. There is no consensus on the optimal method of pain assessment in stroke. A review of the properties of tools should allow an evidence based approach to assessment.

Objectives: We aimed to systematically review published data on pain assessment tools used in stroke, with particular focus on classical test properties of: validity, reliability, feasibility, responsiveness.

Methods: We searched multiple, cross-disciplinary databases for studies evaluating properties of pain assessment tools used in stroke. We assessed risk of bias using the Quality Assessment of Diagnostic Accuracy Studies tool. We used a modified harvest plot to visually represent psychometric properties across tests.

Results: The search yielded 12 relevant articles, describing 10 different tools ( $n=1,106$ participants). There was substantial heterogeneity and an overall high risk of bias. The most commonly assessed property was validity (eight studies) and responsiveness the least (one study). There were no studies with a neuropathic or headache focus. Included tools were either scales or questionnaires. The most commonly assessed tool was the Faces Pain Scale (FPS) (6 studies). The limited number of papers precluded meaningful meta-analysis at level of pain assessment tool or pain syndrome. Even where common data were available across papers, results were conflicting e.g., two papers described FPS as feasible and two described the scale as having feasibility issues.

Conclusion: Robust data on the properties of pain assessment tools for stroke are limited. Our review highlights specific areas where evidence is lacking and could guide further research to identify the best tool(s) for assessing post-stroke pain. Improving feasibility of assessment in stroke survivors should be a future research target.

Systematic Review Registration Number: PROSPERO CRD42019160679 Available online at: https://www.crd.york.ac.uk/prospero/display_record.php?ID=CRD4 2019160679.

Keywords: stroke, stroke care, pain, assessment, evaluation, psychometric 


\section{INTRODUCTION}

Pain is a common problem after stroke (1). Estimates of the frequency of pain vary across studies, depending on the population assessed and whether the focus is incident or prevalent pain. Large cohorts of mild to moderate stroke survivors suggest pain incidence of around $10 \%$ (2), while in smaller cohorts figures range from 30\% during the first months (3), to $48 \%$ at 1 year (4) and $43 \%$ at 10 years (5) after stroke.

Post-stroke pain is associated with disability and reduced quality of life (1). It is independently associated with fatigue (6), depression (7) and has been strongly linked with suicidality $(8,9)$. Pain after stroke can have a variety of etiologies and manifestations, including: shoulder pain, headache, neuropathic pain and exacerbation of pre-existing pain. Pain symptoms can present at any point during stroke recovery and may progress to chronic pain if not recognized and treated appropriately.

The first step in managing post-stroke pain is recognition and measurement. However, management of pain has not always been given the same priority as other aspects of stroke care such as instituting secondary prevention (10). Pain assessment is a complicated task made more challenging in the context of stroke. Since pain is a subjective experience, self-report scales and questionnaires are the most commonly employed pain assessment tools in clinical practice and pain may be part of a more general health related quality of life assessment (11). However, stroke impairments such as cognitive decline and communication issues may make it difficult for stroke survivors to communicate the presence and experience of pain using these tools $(12,13)$. Other impairments such as visual issues or loss of motor skills may further complicate the use of self-completion questionnaires or visual analog scales.

Accepting these caveats, there is a range of pain assessment tools available that could be used with stroke survivors. Some are generic, some are specific to a certain pain syndrome and some are developed exclusively for stroke. At present there is no consensus on the best approach to assessing post-stroke pain and no standardized tool is recommended for research or practice (14). In the absence of a gold standard pain assessment in stroke survivors and with the great variety of assessment tools available, clinicians may struggle to know the most appropriate approach for their patients. The choice of assessment tools should be guided by evidence, particularly, the psychometric properties of the pain assessment tools available. Classical test features such as validity and responsiveness have been described for certain pain tools, however, equally important are end-user evaluations such as acceptability and feasibility within the person's healthcare setting.

A summary of psychometric properties of pain assessment tools could help clinicians and researchers choose the most appropriate measure, highlighting strengths and limitations and also showing where new evidence is needed. Thus, we conducted a systematic review to compare methods of pain assessment following stroke with a particular focus on properties of validity, reliability, feasibility, and responsiveness.

\section{METHODS}

We performed a systematic review, following best practice (15) and where appropriate Preferred Reporting Items for Systematic Reviews and Meta-Analyses (PRISMA) reporting guidance (16). Two assessors (SE, TQ) performed all aspects of title selection, data extraction and analyses with disagreements resolved through discussion.

As our focus was test properties, we structured our review question using the format recommended for test accuracy evidence synthesis (17).

- Index test: Any measure of pain that gives an objective read out.

- Reference standard: Any measure that provides data on the classical test properties of interest namely validity, reliability, feasibility and responsiveness.

- Condition: Stroke of any kind and at any stage in stroke journey.

- Setting: Any healthcare setting.

\section{Search Strategy}

We searched the following databases, chosen to represent the various disciplines that may assess post-stroke pain: Medline (Ovid), Embase (Ovid), CINAHL (EBSCO) and PsychInfo (EBSCO). All were searched from inception to 1st May 2020. Search concepts were "stroke" and "pain" and "assessment." We used validated search filters for "stroke" and "pain," taken from the relevant Cochrane review group (Supplementary Materials). We complemented our search by contacting members of an international stroke pain research group to ensure we had not missed relevant studies.

We screened titles, abstracts and then full text to inform decisions on inclusion. Forward and backward citation searching was conducted for relevant studies using Web of Science functionality. As a test of search validity, we pre-specified two papers (one original research and one review) that should be returned on our literature search $(1,18)$. As a further test we cross-checked our included papers with a systematic review of pain assessment in aphasia, recognizing that the topics were distinct but were likely to have considerable overlap (14).

\section{Selection Criteria}

The population of interest was adult stroke survivors at any stage of recovery. We did not include traumatic brain injury. If a mixed population was included, stroke had to represent more than $75 \%$ of the group. The test of interest was any form of pain assessment, including scales, questionnaires, observations and other patient reported outcome measures. Outcomes of interest were psychometric properties of the tools as defined below. We included studies of any quantitative design, conducted in any healthcare setting, noting setting as part of our data extraction. We only included studies published in peer reviewed journals but applied no other restrictions. 


\section{Data Collection Process and Data Items}

We designed and piloted a bespoke data collection form. We used the research paper that informed our internal validation for piloting (18).

We collected data on the following:

Study details: publication date, country, study design (i.e., cross-sectional, prospective, retrospective), psychometric properties assessed (validity, feasibility, intra/inter-reliability, responsivity), sample size.

Stroke details: stroke classification (for example ischaemic or haemorrhagic), time since stroke, setting (classified as: acute stroke unit, rehabilitation, outpatient, community, using descriptions in the original paper), inclusion/exclusion criteria in original study, noting if there were specific exclusions relating to language or cognition.

Pain assessment: type of pain (see below), method(s) of pain assessment (i.e., pain scales, questionnaires, stroke specific or generic), pain assessor(s) (i.e., researcher or clinical discipline). For articles comparing multiple methods of pain assessment, we included all tools and recorded the primary pain assessment tool.

\section{Categorization of Pain Syndromes}

We categorized pain using the following pre-specified labels: neuropathic, nociceptive (noting the site i.e., lower limb), headache or experimental (i.e., investigator induced pain). We classified stroke shoulder pain as a distinct category as it can include both nociceptive and neuropathic elements. Our pain classification was based on the description in the original paper. Where the nature of the pain syndrome was not clear, two reviewers (SE, TQ) discussed and came to consensus. For some papers, lack of detail precluded applying any label with certainty, and these were categorized as "non-specified."

\section{Psychometric Properties}

We were interested in the following psychometric properties: validity, reliability, feasibility, responsiveness. These were defined as $(19,20)$ :

- Validity: the extent to which an instrument measures what is intended, in this case, is the tool a measure of pain? The concept of "accuracy" would be included as a measure of validity.

- Reliability: the internal consistency of an instrument, and the degree to which it is free from error on repeated. We included measures of inter-observer, intra-observer and internal reliability.

- Feasibility: usability, and acceptability of an instrument from the perspective of assessors and those being assessed.

- Responsiveness: the ability of the instrument to distinguish clinically important changes over time.

On initial scoping it became clear that a traditional quantitative meta-analysis would not be possible, due to the substantial clinical heterogeneity across studies in terms of populations assessed, methods used, nature of pain assessments and psychometric properties described. To allow cross-study comparisons, we created summary measures of the study findings at the level of the psychometric property studied. Our categorization was based on the conclusions of the original paper and was agreed by consensus of two assessors (SE, TQ). We classified results as positive, neutral or inconclusive.

\section{Risk of Bias}

We assessed risk of bias for included studies at the outcome level. Two (SE, TQ) investigators individually assessed papers and agreed final grading. No single quality assessment tool would be suitable for the variety of methodologies that were included in our eligible papers. We elected to use the Quality Assessment of Diagnostic Accuracy Studies 2 (QUADAS-2) tool (21). QUADAS2 is designed for assessing studies of test accuracy and uses a framework suited to our review with assessment of bias and applicability across four domains: patient selection, index tests, reference standard, flow and timing (17). As recommended, we took the original QUADAS-2 anchoring statements and modified to suit our review (modified domain questions included in Supplementary Materials). We used robvis R package software to create summary "traffic light" plots (22). Due to the limited number of studies and heterogeneity in summary measures we did not perform quantitative assessment for publication bias.

\section{Evidence Synthesis}

We created two summary tables (Tables 1, 2): the first describes key characteristics of the included articles and the second summarizes their quantitative results. Our data were heterogeneous and required representation of differing constructs across various axes. To allow a visual representation that included pain syndrome, pain assessment tool and results of psychometric testing across various constructs we developed a visual plot using a modified harvest plot (23). We first created a matrix that plotted results by pain assessment tool (we created space in the plot for subcategorising by pain scales and questionnaires) against each psychometric property of interest. We color-coded according to pain type with one unit of plot space per study/experiment and then assigned the results of the study as positive (above a horizontal line of no effect), neutral (below the line) or inconclusive (crossing the line).

\section{RESULTS}

The primary search yielded 2,851 articles, with $12(9,18,24-$ 33) papers $(n=1,106$ participants) meeting the inclusion criteria (Figure 1). Our search results suggested a valid search as they included the two pre-selected papers and had all the relevant studies from the previous aphasia review. The number of participants in eligible papers ranged from 19 to 388. The most commonly employed design was cross-sectional $(n=6)$ with the majority of studies $(n=6)$ conducted in a rehabilitation setting (Table 1, Supplementary Materials).

In total, 10 different pain scales and questionnaires were assessed across the 12 studies (Table 1). These were: Visual Analog Scale (VAS [differing scales described as VAS]), the Faces Pain Scale (including a revised version), Numerical Rating Scale, and various combinations of these; the Pain Assessment Scale for Seniors with Severe Dementia-II (PACSLAC-II), and three questionnaires: AbilityQ, ShoulderQ and the neuropathic pain 
TABLE 1 | Key Characteristics of included papers.

\begin{tabular}{|c|c|c|c|c|c|c|c|c|c|}
\hline Author/s & Study design & $\begin{array}{l}\text { Psychometric } \\
\text { properties } \\
\text { assessed }\end{array}$ & $\begin{array}{l}\text { Number } \\
\text { included }\end{array}$ & $\begin{array}{l}\text { Age (years) } \\
\text { (mean, SD) }\end{array}$ & Stroke setting & Exclusion criteria & Type of pain & $\begin{array}{l}\text { Pain } \\
\text { assessment } \\
\text { tool }\end{array}$ & Pain assessor \\
\hline 1. Benaim (9) & Cross-sectional & Validity, reliability & 127 & $63 \pm 8$ & Rehabilitation & $\begin{array}{l}\text { cognitive impairments, } \\
\text { psychiatric disorders }\end{array}$ & Shoulder pain & FPS & Unknown \\
\hline 2. Chuang (24) & Prospective & Reliability & 50 & $52.6 \pm 11.0$ & Outpatient & $\begin{array}{l}\text { other acute pain } \\
\text { conditions, major } \\
\text { medical problems, } \\
\text { psychological } \\
\text { impairments, aphasia }\end{array}$ & $\begin{array}{l}\text { Arm/shoulder } \\
\text { pain }\end{array}$ & v-NPRS-FPS & $\begin{array}{l}\text { Clinical staff } \\
\text { (rehabilitation } \\
\text { physicians) }\end{array}$ \\
\hline 3. Dogan (25) & Case control & Validity & $\begin{array}{l}60 \text { including } \\
\text { non-stroke control } \\
(n=30)\end{array}$ & $64.2 \pm 9.42$ & Rehabilitation & $\begin{array}{l}\text { Pre-existing pain } \\
\text { conditions, cognitive } \\
\text { impairment, aphasia }\end{array}$ & Shoulder pain & FPS & Unknown \\
\hline $\begin{array}{l}\text { 4. Korner-Bitensky } \\
\text { (26) }\end{array}$ & Cross-sectional & Validity & 90 & Not available & Rehabilitation & $\begin{array}{l}\text { cognitive impairments, } \\
\text { central post-stroke pain } \\
\text { syndrome }\end{array}$ & $\begin{array}{l}\text { Experimental } \\
\text { (thermal) }\end{array}$ & $10-\mathrm{cm} \mathrm{v}$-VAS & $\begin{array}{l}\text { Clinical staff (SLT), } \\
\text { researcher }\end{array}$ \\
\hline 5. Price (18) & Case control & Feasibility, validity & $\begin{array}{l}144 \text { including } \\
\text { non-stroke } \\
\text { controls }(n=48)\end{array}$ & 72.5 mean & Acute stroke unit & $\begin{array}{l}\text { reduced conscious } \\
\text { level or dysphasic }\end{array}$ & $\begin{array}{l}\text { Experimental } \\
\text { (pressure) }\end{array}$ & $\mathrm{V} / \mathrm{m} / \mathrm{h}-\mathrm{VAS}$ & Researcher \\
\hline 6. Smith (27) & Retrospective & Feasibility & 388 & 77 (IQR:66-86) & Acute stroke unit & subsequent strokes & Not specified & $\begin{array}{l}\text { FPS and/or } \\
\text { NRS }\end{array}$ & $\begin{array}{l}\text { Clinical staff } \\
\text { (Nurses) }\end{array}$ \\
\hline 7. Roosink (28) & Cross-sectional & Validity & 19 & $57.5 \pm 7.5$ & Rehabilitation & $\begin{array}{l}\text { other chronic pain } \\
\text { conditions, neurological } \\
\text { deficits }\end{array}$ & Shoulder pain & DN4 & Unknown \\
\hline $\begin{array}{l}\text { 8. Turner-Stokes } \\
\text { (29) }\end{array}$ & Cross-sectional & $\begin{array}{l}\text { Validity, reliability, } \\
\text { feasibility }\end{array}$ & 49 & $52.6 \pm 3.1$ & Rehabilitation & not specified & Shoulder pain & $\begin{array}{l}\text { AbilityQ, } \\
\text { ShoulderQ }\end{array}$ & Researcher \\
\hline $\begin{array}{l}\text { 9. Turner-Stokes } \\
\text { (30) }\end{array}$ & Retrospective & Responsiveness & 30 & $47.2 \pm 2.2$ & Rehabilitation & not specified & Shoulder pain & $\begin{array}{l}\text { AbilityQ, } \\
\text { ShoulderQ }\end{array}$ & $\begin{array}{l}\text { Clinical staff } \\
\text { (Nurses) }\end{array}$ \\
\hline $\begin{array}{l}\text { 10. Mandysová } \\
\text { (31) }\end{array}$ & Cross-sectional & $\begin{array}{l}\text { Validity, reliability, } \\
\text { feasibility }\end{array}$ & 80 & $\begin{array}{l}71.0 \pm 13.7 \\
\text { (range 22-94) }\end{array}$ & Acute stroke unit & $\begin{array}{l}\text { reduced conscious } \\
\text { level }\end{array}$ & Not specified & $\begin{array}{l}\text { VAS/NRS, } \\
\text { NRS, FPS-R }\end{array}$ & Researcher \\
\hline 11. Pomeroy (32) & Prospective & Reliability & 33 & 74 (range 57-89) & Community & $\begin{array}{l}\text { reduced conscious } \\
\text { level, other pain } \\
\text { conditions, no irregular } \\
\text { pain medication, no } \\
\text { neurological/MSK } \\
\text { disorders }\end{array}$ & Shoulder pain & $10-\mathrm{cm} \mathrm{v}$-VAS & $\begin{array}{l}\text { Clinical staff } \\
\text { (physiotherapist) }\end{array}$ \\
\hline 12. Soares (33) & Cross-sectional & Reliability, validity & 36 & $\begin{array}{l}61 \text { median (range } \\
46-71.75)\end{array}$ & Acute stroke unit & neurological disorders & $\begin{array}{l}\text { Experimental } \\
\text { (mechanical) }\end{array}$ & PACSLAC-\| & $\begin{array}{l}\text { Clinical staff } \\
\text { (Neurology nurses) }\end{array}$ \\
\hline
\end{tabular}

Study design and setting were categorized and agreed by two raters (SE, TQ).

FPS, Faces Pain Scale; NRS/NPRS, Numerical Rating Scale; VAS, Visual Analog Scale, v-/m-/h-, vertical/mechanical/horizontal.

NPRS-FPS and VAS/NRS indicate combined versions of scales DN4, neuropathic pain diagnostic questionnaire: PACSLAC-II. Pain Assessment Scale for Seniors with Severe Dementia-II.

SLT, Speech and Language Therapy.

N.B. more comprehensive version of table is available in Supplementary Materials. 
TABLE 2 | Summary of results from included articles.

\begin{tabular}{|c|c|c|}
\hline Author/s & $\begin{array}{l}\text { Pain assessment } \\
\text { (comparator) }\end{array}$ & Results \\
\hline 1. Benaim (9) & FPS (VAS, VRS) & $\begin{array}{l}\text { - Validity: Correlation of FPS with VAS and VRS in both left and right hemisphere stroke }(r= \\
\text { - } r .65-0.82) \\
\text { - Reliability: } \\
\text { - Inter-rater:K:0.64 (SE }=0.11) \text { and } K: 0.44(0.09) \text { in left and right hemisphere stroke respectively. } \\
\text { - Intra-rater:K:0.74 (0.13) and } K: 0.53(0.10) \text { in left and right hemisphere stroke respectively. } \\
\text { Feasibility: FPS was preferred in left hemisphere stroke, VAS was preferred in right } \\
\text { hemisphere stroke. }\end{array}$ \\
\hline 2. Chuang (24) & v-NPRS-FPS & $\begin{array}{l}\text { - Reliability (intra-rater):ICC }=0.82(\mathrm{SE}=0.81) \text {, [smallest real difference }=1.87] \text {. } \\
\text { - No significant systematic bias between repeated measurements for NPRS-FPS. } \\
\text { - High level of stability and minimal temporal variation, range of limits of agreement }(-2.50 \text { to } 1.90)\end{array}$ \\
\hline 3. Dogan (25) & FPS (VAS, LPS, NRS) & $\begin{array}{l}\text { - Validity: Correlation of FPS with other pain scales in both groups }(r=0.95-0.97 \text { and } \\
0.67-0.93 \text {, respectively). }\end{array}$ \\
\hline 4. Korner-Bitensky (26) & 10-cm v-VAS & $\begin{array}{l}\text { - Validity: No between group difference in pain discrimination }(p=0.75) \text {. } \\
\text { - Repeated-measures ANOVA revealed no effect of group. }\end{array}$ \\
\hline 6. Smith (27) & FPS, NRS & $\begin{array}{l}\text { - Feasibility: } 13.4 \% \text { individuals unable to provide a meaningful response to either FPS or NRS. } \\
\text { - Validity: Maximum NRS values correlated with length of stay }(r=0.29, P<0.0001) \text {, stroke } \\
\text { severity }(r=0.212, P=0.0008) \text {, and number of sites of pain }(r=0.20, P=0.007) \text {. }\end{array}$ \\
\hline 7. Roosink (28) & DN4 (NRS) & $\begin{array}{l}\text { - Validity: DN4+ classified patients reported: constant pain [DN4+: } n=4(44 \%) ; \mathrm{DN} 4-: n=0] \text { higher } \\
\text { pain intensity [DN4+=4.7 (SD = 2.9); DN4- }=2.5(\mathrm{SD}=2.4)] \text { higher impact of pain on daily living } \\
\text { DN4+=5.9 (SD }=4.8), \mathrm{DN} 4-=2.0(\mathrm{SD}=2.6) \text { more frequent loss of cold sensation [DN4+: } n= \\
7(78 \%) ; \mathrm{DN} 4-: n=2(20 \%)] \\
\text { - Signs and symptoms suggestive of neuropathic or nociceptive pain corresponded to DN4+ and } \\
\text { DN4- respectively. }\end{array}$ \\
\hline 8. Turner-Stokes (29) & $\begin{array}{l}\text { AbilityQ, ShoulderQ } \\
\text { (VAS) }\end{array}$ & $\begin{array}{l}\text { - Validity: VAS agreement } \pm 1 \text { on a } 10-\text { point scale was } 36-59 \% \text { with intraclass correlation coefficients } \\
\text { O.50-0.60 }(p<0.01) \text {. } \\
\text { - Reliability: Agreement for individual questions } 55-88 \% ; K: 0.07-0.79 \\
\text { - Repeatability of ShoulderQ } 36-72 \%, K: 0.16-0.56 \text {. } \\
\text { - Feasibility: } N=31(63 \%) \text { required help in completing AbilityQ. }\end{array}$ \\
\hline 10. Mandysová (31) & VAS/NRS, NRS, FPS-R & $\begin{array}{l}\text { - Validity: } n=19(24 \%) \text { reported pain using at least one scale. } \\
\text { - Spearman correlation was } 0.997(p<0.001) \text { between VAS/NRS and NRS. } \\
\text { - Feasibility: NRS had the highest preference ranking (ranking first or second in } 75 \% \text { cases). }\end{array}$ \\
\hline 11. Pomeroy (32) & 10-cm v-VAS & $\begin{array}{l}\text { - Inter-rater reliability: ICC: } 0.79 \text { for intensity, } 0.75 \text { for frequency and } 0.62 \text { for affective response. } \\
\text { - Wide limits of agreement and significant rater bias reported for } 6 / 27 \text { ratings. } \\
\text { - Intra-rater reliability:ICC:0.70 for intensity, } 0.77 \text { for frequency and } 0.69 \text { for affective response. }\end{array}$ \\
\hline 12. Soares (33) & PACSLAC-\| & $\begin{array}{l}\text { - Validity: PACSLAC-II differentiated 4.5-lb stimulus versus } 2-1 \mathrm{~b}(\mathrm{p}=0.03) \text { or } 0 \mathrm{lb}(\mathrm{p}=0.05) \text {. } \\
\text { - Reliability (internal): Cronbach } \alpha: 0.87,0.94 \text {, and } 0.96 \text { for weights of } 0,2 \text {, and } 4.5 \mathrm{lb} \text {, respectively. }\end{array}$ \\
\hline
\end{tabular}

FPS, Faces Pain Scale; NRS/NPRS, Numerical Rating Scale; VAS, Visual Analog Scale; LPS, Likert Pain Scale; FPRS, Four-point rating scale; v-/m-/h-, vertical/mechanical/horizontal, visual graphic rating scale (NGRS); NPRS-FPS and VAS/NRS indicate combined versions of scales DN4=neuropathic pain diagnostic questionnaire (DN4+, neuropathic pain reported; DN4-, no neuropathic pain reported); PACSLAC-II, Pain Assessment Scale for Seniors with Severe Dementia-II.

diagnostic questionnaire (DN4). Of the included assessments, only the ShoulderQ was developed specifically for stroke. The Faces Pain Scale was the most commonly reported, with a version of this scale used in six of the 12 studies.

Where a pain category was described, the most commonly studied was shoulder pain. Neuropathic pain and Headache were not studied, except possibly in those papers that did not differentiate pain type. There was heterogeneity in the tools assessed for each pain category, with no pain category having more than two studies using a common tool (Table 3).

There was a high risk of bias detected in the majority of included papers ( $n=8$; Figure 2 ). Highest risk of bias and issues 


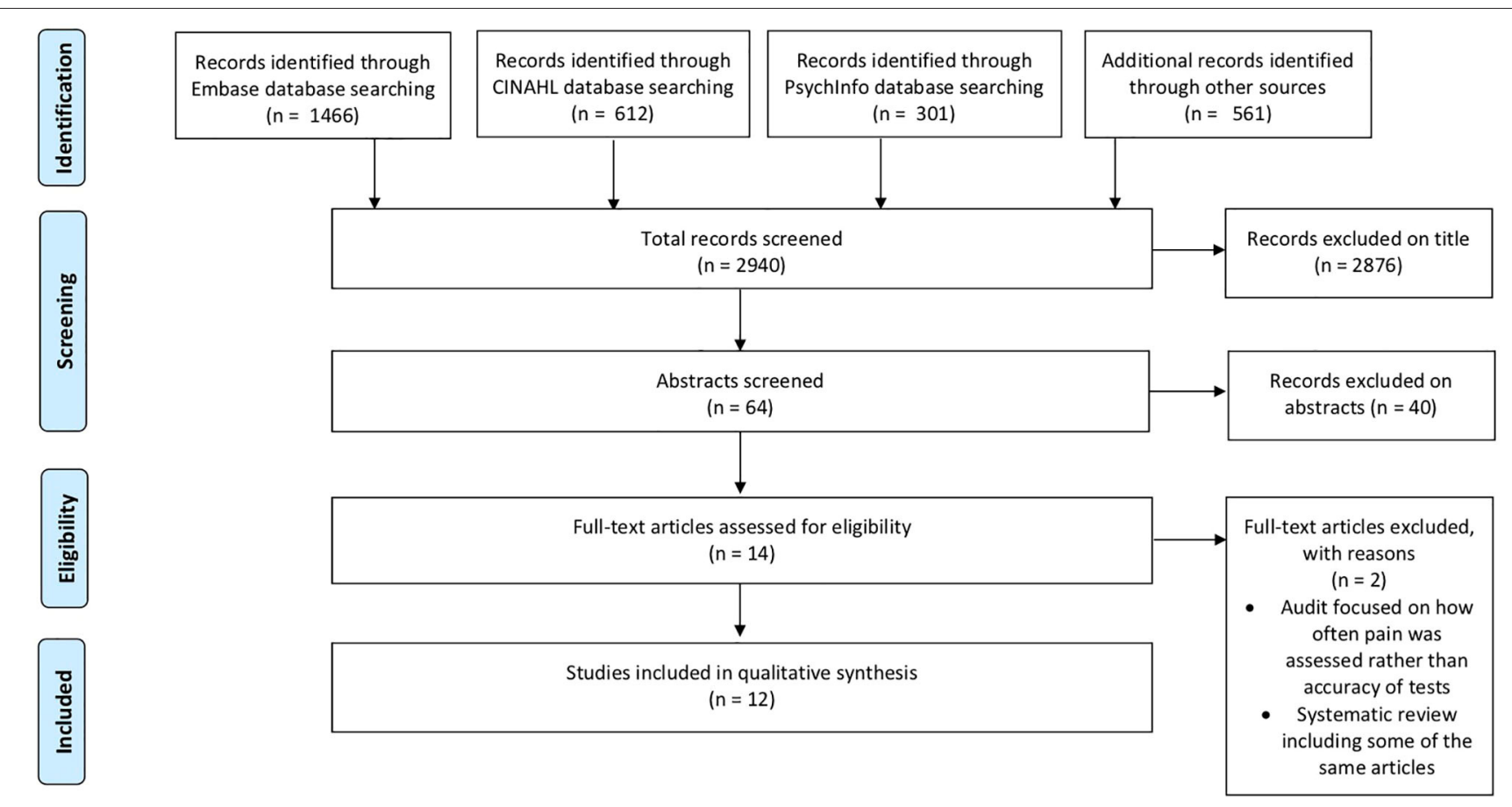

FIGURE 1 | PRISMA Flow chart for selection of studies for systematic review. The first search was performed on 31st July 2019; to ensure the review was up to date we ran a repeat search on 08/05/2020. The PRISMA contains an aggregate of both searches.

TABLE 3 | Cross-tabulation of pain assessment tool and post stroke pain syndrome.

\begin{tabular}{lllcccccccc}
\hline & \multicolumn{9}{c}{ Pain assessment tool } \\
\cline { 3 - 8 } & & VAS & VAS-NRS & FPS & FPS-NRS & NRS & VRS & ShoulderQ & PACSLAC-11 & DN4 \\
\hline \multirow{2}{*}{ Post-stroke pain syndrome } & Shoulder/arm pain & 1 & 0 & 2 & 1 & 0 & 0 & 2 & 0 \\
& Experimental & 2 & 0 & 0 & 0 & 0 & 0 & 0 & 1 \\
& Not specified & 0 & 1 & 2 & 0 & 2 & 0 & 0 & 0 \\
& Neuropathic & 0 & 0 & 0 & 0 & 0 & 0 & 0 & 0 \\
& Headache & 0 & 0 & 0 & 0 & 0 & 0 & 0 & 0 \\
\hline
\end{tabular}

Each value represents use of a pain assessment tool by according to a post-stroke pain syndrome.

FPS, Faces Pain Scale; NRS/NPRS, Numerical Rating Scale; VAS, Visual Analog Scale; LPS, Likert Pain Scale; FPRS, Four-point rating scale; v-/m-/h-, vertical/mechanical/horizontal, visual graphic rating scale (NGRS), NPRS-FPS and VAS/NRS indicate combined versions of scales DN4, neuropathic pain diagnostic questionnaire (DN4+, neuropathic pain reported; DN4-, no neuropathic pain reported); PACSLAC-II, Pain Assessment Scale for Seniors with Severe Dementia-II.

with generalisability was seen for the domain of patient selection ( $n=10$; judged high risk). This was due to exclusion of patients for whom pain assessment would be expected in clinical practice, including those with pre-stroke pain ( $n=5$ papers), aphasia $(n=3)$ and cognitive impairment $(n=3)$. There was poor reporting of study methods relevant to the risk of bias assessment, particularly around blinding of results when a study compared scales. Only four papers were judged to have overall low risk of bias $(18,24,32,33)$.

We created a visual synthesis of the psychometric properties of the tools used to assess pain as a modified harvest plot (Figure 3). The harvest plot approach allows visual display of data across several axes in one figure. We represented each study as a single unit (square), and color coded based on pain type. A horizontal line that bisected each row was a line of uncertain effect, if a study claimed that the psychometric property of interest was "good" i.e., acceptable for clinical use then the study was placed above the line, if the paper reported that the study was "poor" i.e., would not be suitable it was placed below the line.

All psychometric domains of interest were reviewed by at least one study, although the statistical approach to these assessments varied. Validity was the psychometric property evaluated most frequently $(n=8)$, and responsiveness was only considered by one study. In general the pain scales assessed were judged to be valid measures by the authors of the studies, with only two studies reporting concerns around validity (Figure 3). A version of the Faces Pain Scale was the most commonly assessed, with evaluations of validity $(n=3)$, reliability $(n=3)$, and feasibility 


\begin{tabular}{|c|c|c|c|c|c|}
\hline & Domain 1: Patient Selection & Domain 2: Index Test & $\begin{array}{l}\text { Risk of bias domains } \\
\text { Domain } 3 \text { : Reference Standard } \\
\end{array}$ & Domain 4: Flow and Timing & Overall \\
\hline $\begin{array}{l}\text { 1. Benaim } \\
\text { (2007) }\end{array}$ & & + & + & & \\
\hline $\begin{array}{l}\text { 2. Chung } \\
\text { (2014) }\end{array}$ & & + & ? & & $\oplus$ \\
\hline $\begin{array}{l}\text { 3. Dogan } \\
\text { (2010) }\end{array}$ & & ? & ? & ? & \\
\hline $\begin{array}{l}\begin{array}{l}\text { 4. Korner- } \\
\text { Bitingsky } \\
(2006)\end{array} \\
\end{array}$ & & ? & ? & & \\
\hline $\begin{array}{l}\text { 5. Price } \\
\text { (1999) }\end{array}$ & & + & + & 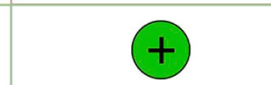 & $\oplus$ \\
\hline $\begin{array}{l}\text { 6. Smith } \\
(2013)\end{array}$ & & ? & ? & & \\
\hline $\begin{array}{l}\text { 7. Roosink } \\
\text { (2012) }\end{array}$ & & $?$ & + & + & \\
\hline $\begin{array}{l}\text { 8. Turner- } \\
\text { stokes- } \\
\text { (2003) }\end{array}$ & & ? & ? & & \\
\hline $\begin{array}{l}9 . \text { Turner- } \\
\text { Stotoses } \\
\text { (2006) } \\
\end{array}$ & & $?$ & $?$ & + & \\
\hline $\begin{array}{l}\text { 10. } \\
\text { Mandysova } \\
(2016)\end{array}$ & & $?$ & ? & $\oplus$ & . \\
\hline $\begin{array}{l}11 . \\
\text { Pomeroy } \\
\text { (2000) }\end{array}$ & & + & + & + & $\oplus$ \\
\hline 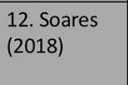 & $\oplus$ & $\oplus$ & + & + & $\oplus$ \\
\hline & & & & & \\
\hline
\end{tabular}

FIGURE 2 | Traffic Light plot for risk of bias in individual studies.

$(n=2)$. However, results were conflicting, for example feasibility of FPS was assessed as good, neutral and poor across the studies (Figure 3).

\section{DISCUSSION}

We aimed to systematically review the psychometrics of pain assessment tools when used with stroke survivors. We found a limited literature with substantial heterogeneity in the tools used, the research methods employed and the properties assessed. The available data were limited by risk of bias and modest sample sizes. Thus, we are unable to recommend a preferred tool based on published psychometric properties. However, through our evidence synthesis, we have highlighted important evidence gaps that can inform the direction of future research activity in the pain assessment space.
Our mapping of the evidence using the harvest plot demonstrates the many limitations in the evidence base. Of the four key psychometric properties, there was little information on reliability, and responsiveness. Even where there was a portfolio of papers on a single tool it was difficult to draw conclusions. There were more studies on visual scales than questionnaires, with few studies using a scale specifically developed for stroke and no studies with a neuropathic or headache pain focus.

Our findings of inconsistent and inconclusive evidence are not unique to stroke. A previous review of pain assessment in aphasia concluded that "a feasible, reliable and valid pain assessment instrument is not yet available" (14). Dementia is another clinical condition where pain is common but potentially difficult to assess. Although there is more published literature on dementia pain assessment tools (34), conclusions of reviews are similar "limited evidence about reliability, validity and clinical utility" (35). This seems a missed opportunity, as well as the clinical 


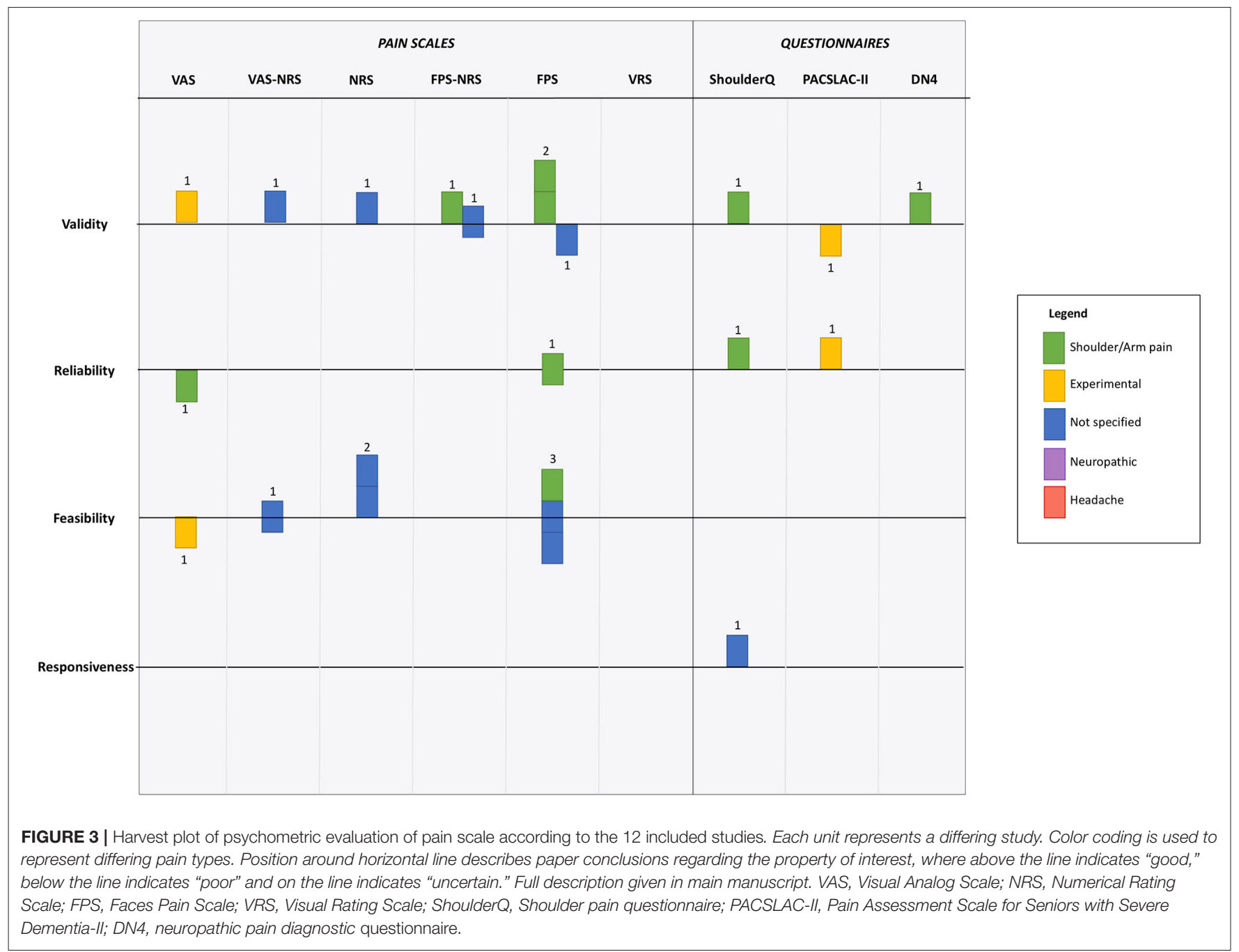

importance of looking for pain, quantitative pain assessment could be a useful research outcome (36).

Our assessment of risk of bias suggests common areas of concern particularly around reporting and generalisability. Exclusion of stroke survivors with aphasia, dementia or comorbidity threatens the external validity of study results. Similar exclusions have been demonstrated in other aspects of stroke assessment (37). Certain scales may not be suitable for all stroke impairments, but simply excluding those people who may struggle to complete an assessment creates bias in any resulting estimates (38).

Our review has several strengths. We performed a comprehensive search, followed best practice guidance and embedded internal validation steps. Given the disparate nature of relevant studies, we used non-traditional methods for evidence synthesis and assessment of quality. There are limitations to our approach. Despite internal and external validity steps we may have missed relevant papers. We were not able to perform quantitative meta-analysis either at an aggregate level or at the level of differing pain types, but instead used a relatively novel method of visual data synthesis. Our modified harvest plot approach gives a summary of the totality of the data across various axes, allowing for visual comparisons across tools. This approach could be applied in other complex reviews with substantial heterogeneity in the supporting literature.

Despite the prevalence of post-stroke pain, studies describing the best way to assess for this problem are limited in number and quality. Our evidence mapping and quality assessments highlight particular pain syndromes and tests that have no empirical evidence base. No pain assessment had sufficient data to be considered definitive and further, robust research for any pain tool would be a welcome addition.

In light of this uncertainty what conclusions can be made? Patient based scales, such as faces pain scale, seem to have the most supporting evidence and are a valid means to assess pain. Our review suggests there are many evidence gaps requiring future research, but methods to improve feasibility of assessment seem an important target. 


\section{DATA AVAILABILITY STATEMENT}

All datasets presented in this study are included in the article/Supplementary Material.

\section{AUTHOR CONTRIBUTIONS}

SE contributed to all aspects of searching, data extraction and analysis, provided critical review, and contributed to draft manuscripts. AI assisted with data extraction, provided critical review, and contributed to draft manuscripts. GC-L provided critical review, assisted with formatting, and contributed to draft manuscripts. EC provided critical review, assisted with formatting, and contributed to draft manuscripts. MB provided critical review, expert aphasia advice, and contributed to draft manuscripts. SM provided critical review and contributed to draft manuscripts. TS provided critical review and contributed to draft manuscripts. GM devised the study question, coordinated the team, and contributed to draft manuscripts. TQ provided critical review and contributed to

\section{REFERENCES}

1. Harrison RA, Field TS. Post stroke pain: identification, assessment, and therapy. Cerebrovasc Dis. (2015) 39:190-201. doi: 10.1159/000375397

2. O’Donnell MJ, Diener H-C, Sacco RL, Panju AA, Vinisko R, Yusuf S. Chronic pain syndromes after ischemic stroke. Stroke. (2013) 44:123843. doi: 10.1161/STROKEAHA.111.671008

3. Paolucci S, Iosa M, Toni D, Barbanti P, Bovi P, Cavallini A, et al. Prevalence and time course of post-stroke pain: a multicenter prospective hospital-based study. Pain Med. (2015) 17:pnv019. doi: 10.1093/pm/pnv019

4. Naess H, Lunde L, Brogger J. The triad of pain, fatigue and depression in ischemic stroke patients: the bergen stroke study. Cerebrovasc Dis. (2012) 33:461-5. doi: 10.1159/000336760

5. Jönsson AC, Delavaran H, Iwarsson S, Ståhl A, Norrving B, Lindgren A. Functional status and patient-reported outcome 10 years after stroke. Stroke. (2014) 45:1784-90. doi: 10.1161/STROKEAHA.114.005164

6. Hoang CLN, Salle J, Mandigout S, Hamonet J, Macian-Montoro F, Daviet J. Physical factors associated with fatigue after stroke: an exploratory study. Top Stroke Rehabil. (2012) 19:369-76. doi: 10.1310/tsr1905-369

7. Lundström E, Smits A, Terént A, Borg J. Risk factors for strokerelated pain 1 year after first-ever stroke. Eur J Neurol. (2009) 16:18893. doi: 10.1111/j.1468-1331.2008.02378.x

8. Tang WK, Liang H, Mok V, Ungvari GS, Wong K. Is pain associated with suicidality in stroke? Arch Phys Med Rehabil. (2013) 94:8636. doi: 10.1016/j.apmr.2012.11.044

9. Benaim C, Froger J, Cazottes C, Gueben D, Porte M, Desnuelle C, et al. Use of the faces pain scale by left and right hemispheric stroke patients. Pain. (2007) 128:52-8. doi: 10.1016/j.pain.2006.08.029

10. McArthur KS, Quinn TJ, Higgins P, Langhorne P. Post-acute care and secondary prevention after ischaemic stroke. BMJ. (2011) 342:d2083. doi: 10.1136/bmj.d2083

11. Dansie EJ, Turk DC. Assessment of patients with chronic pain. Br J Anaesth. (2013) 111:19-25. doi: 10.1093/bja/aet124

12. Delpont B, Blanc C, Osseby GV, Hervieu-Bègue M, Giroud M, Béjot Y. Pain after stroke: a review. Rev Neurol. (2018) 174:671-4. doi: 10.1016/j.neurol.2017.11.011

13. Quinn TJ, Elliott E, Langhorne P. Cognitive and mood assessment tools for use in stroke. Stroke. (2018) 49:483-90 doi: 10.1161/STROKEAHA.117.016994

14. de Vries NJC, Sloot PH, Achterberg WP. Pain and pain assessment in stroke patients with aphasia: a systematic review. Aphasiology. (2017) 31:70319. doi: 10.1080/02687038.2016.1254150 draft manuscripts. All authors contributed to the article and approved the submitted version.

\section{FUNDING}

SE was supported by a University of Glasgow studentship; the Pain in Stroke Research Group is supported by a British Association of Physicians and National Institute of Health Research Grant.

\section{ACKNOWLEDGMENTS}

We acknowledge the support of the Pain in Stroke Research Group.

\section{SUPPLEMENTARY MATERIAL}

The Supplementary Material for this article can be found online at: https://www.frontiersin.org/articles/10.3389/fneur. 2020.00792/full\#supplementary-material

15. Shenkin SD, Harrison JK, Wilkinson T, Dodds RM, Ioannidis JPA. Systematic reviews: guidance relevant for studies of older people. Age Ageing. (2017) 46:722-8. doi: 10.1093/ageing/afx105

16. Moher D, Liberati A, Tetzlaff J, Altman D.G, Group P. Preferred reporting items for systematic reviews and meta-analyses: the PRISMA statement. J Clin Epidemiol. (2009) 62:1006-12. doi: 10.1016/j.jclinepi.2009. 06.005

17. Takwoingi Y, Quinn TJ. Review of diagnostic test accuracy (DTA) studies in older people. Age Ageing. (2018) 47:349-55. doi: 10.1093/ageing/afy023

18. Price CIM, Curless RH, Rodgers H, Price CI, Curless RH, Rodgers H. Can stroke patients use visual analog scales? Stroke. (1999) 30:135761. doi: 10.1161/01.STR.30.7.1357

19. Milne A, Johnson JA, Tennant M, Rudnisky C, Dryden DM. Measuring Health-Related Quality of Life for Patients With Diabetic Retinopathy. Rockville, MD: Agency for Healthcare Research and Quality. (2012).

20. Qi S, Diane J, Kay D. The psychometric properties, feasibility and utility of behavioural-observation methods in pain assessment of cognitively impaired elderly people in acute and long-term care: a systematic review. JBI Libr Syst Rev. (2012) 10:977-1085. doi: 10.11124/jbisrir-2012-62

21. Whiting PF, Rutjes AWS, Westwood ME, Mallett S, Deeks JJ Reitsma JB, et al. QUADAS-2: a revised tool for the quality assessment of diagnostic accuracy studies. Ann Intern Med. (2011) 155:529-36. doi: 10.7326/0003-4819-155-8-201110180-00009

22. McGuinness LA. Robvis: An R Package and Web Application for Visualising Risk-of-Bias Assessments. (2019). Available online at: https://github.com/ mcguinlu/robvis (accessed Jan 2020).

23. Ogilvie D, Fayter D, Petticrew M, Sowden A, Thomas S, Whitehead $\mathrm{M}$, et al. The harvest plot: a method for synthesising evidence about the differential effects of interventions. BMC Med Res Methodol. (2008) 8:8. doi: 10.1186/1471-2288-8-8

24. Chuang $\mathrm{L}, \mathrm{Wu} \mathrm{C}$, Lin $\mathrm{K}, \mathrm{Hsieh} \mathrm{C}$. Relative and absolute reliability of a vertical numerical pain rating scale supplemented with a faces pain scale after stroke. Phys Ther. (2014) 94:129-38. doi: 10.2522/ptj.20120422

25. Dogan SK, Ay S, Oztuna D, Aytur YK, Evcik D. The utility of the faces pain scale in the assessment of shoulder pain in turkish stroke patients: its relation with quality of life and psychologic status. Int J Rehabil Res. (2010) 33:363-7. doi: 10.1097/MRR.0b013e32833cdef3

26. Korner-Bitensky N, Kehayia E, Tremblay N, Mazer B, Singer F, Tarasuk J, et al. Eliciting information on differential sensation of heat in those with and without poststroke aphasia using a visual analog scale. Stroke. (2006) 37:471-5. doi: 10.1161/01.STR.0000198872.75377.34 
27. Smith JH, Bottemiller KL, Flemming KD, Michael Cutrer F, Strand EA. Inability to self-report pain after a stroke: a population-based study. Pain. (2013) 154:1281-6. doi: 10.1016/j.pain.2013.04.006

28. Roosink M, van Dongen, Robert TM, Renzenbrink GJ, Jzerman IMJ. Classifying post-stroke shoulder pain: can the DN4 be helpful? Eur J Pain. (2011) 15:99-102. doi: 10.1016/j.ejpain.2010.05.012

29. Turner-Stokes L, Rusconi S. Screening for ability to complete a questionnaire: a preliminary evaluation of the abilityQ and shoulderQ for assessing shoulder pain in stroke patients. Clin Rehabil. (2003) 17:150-7. doi: 10.1191/0269215503cr595oa

30. Turner-Stokes L, Jackson D. Assessment of shoulder pain in hemiplegia: sensitivity of the shoulderQ. Disabil Rehabil. (2006) 28:389-95. doi: 10.1080/09638280500287692

31. Mandysová P, Nedvědová A, Ehler E. A comparison of three self-report pain scales in Czech patients with stroke. Cent Eur J Nurs Midwifery. (2017) 8:572-9. doi: 10.15452/CEJNM.2017.08.0004

32. Pomeroy VM, Frames C, Faragher EB, Hesketh A, Hill E, Watson P, et al. Reliability of a measure of post-stroke shoulder pain in patients with and without aphasia and/or unilateral spatial neglect. Clin Rehabil. (2000) 14:58491. doi: 10.1191/0269215500cr365oa

33. Soares CD, Panuganti PK, Shrivastava A, Aroor S, Keinath KM, Bromagen $\mathrm{MC}$, et al. Experimental pain assessment in patients with poststroke aphasia. Neurology. (2018) 91:e793-9. doi: 10.1212/WNL.0000000000 006081

34. Harrison JKH, Noel-Storr AH, Demeyere N, Reynish El, Quinn TJ. Outcome measures in a decadeof dementia and mild cognitive impairment research. Alz Res Ther. (2016) 48:8 doi: 10.1186/s13195-016-0216-8
35. Lichtner V, Dowding D, Esterhuizen P, Closs SJ, Long AF, Corbett A, et al. Pain assessment for people with dementia: a systematic review of systematic reviews of pain assessment tools. BMC Geriatr. (2014) 14:138. doi: 10.1186/1471-2318-14-138

36. Ritchie CW, Terrera GM, Quinn TJ. Dementia trials and dementia tribulations: methodological and analytical challenges in dementia research. Alz Res Therapy. (2015) 7:31. doi: 10.1186/s13195-015-0113-6

37. Pendlebury ST, Chen PJ, Bull L, Silver L, Mehta Z, Rothwell PM. Methodological factors in determining rates of dementia in TIA and stroke: (I) impact of baseline selection bias. Stroke. (2015) 46:6416. doi: 10.1161/STROKEAHA.114.008043

38. Lees RA, Hendry KBA, Broomfield N, Stott D, Larner AJ, Quinn TJ. Cognitive assessment in stroke: feasibility and test properties using differing approaches to scoring of incomplete items. Int J Geriatr Psychiatr. (2017) 32:10728. doi: 10.1002 /gps.4568

Conflict of Interest: The authors declare that the research was conducted in the absence of any commercial or financial relationships that could be construed as a potential conflict of interest.

Copyright (C) 2020 Edwards, Ioannou, Carin-Levy, Cowey, Brady, Morton, Sande, Mead and Quinn. This is an open-access article distributed under the terms of the Creative Commons Attribution License (CC BY). The use, distribution or reproduction in other forums is permitted, provided the original author(s) and the copyright owner(s) are credited and that the original publication in this journal is cited, in accordance with accepted academic practice. No use, distribution or reproduction is permitted which does not comply with these terms. 